\title{
Individualismo Moral e a Sociologia Clássica
}

\author{
Raphael de Oliveira Soares ${ }^{1}$ \\ Recebido em setembro de 2020 \\ Aceito em dezembro de 2020
}

\section{RESUMO}

A sociologia clássica, não obstante tenha, como uma de suas características principais, a pluralidade de abordagens e de paradigmas, partilha, entre seus autores, de uma normatividade comum, isto é, de um mesmo ideal de sociedade justa. Argumentaremos, ao longo do texto, que a partir de um individualismo moral, tanto Marx, quanto Weber, Durkheim, Simmel e Tocqueville, fornecem, por diferentes vias, teorias cujo objetivo se dirige a formulação de diretrizes práticas para o pleno desenvolvimento das capacidades e liberdades individuais. O indivíduo universal, e não o grupo, é a meta. Portanto, a sociologia clássica faz o diagnóstico das fontes de exploração e dominação que impedem o livre desenvolvimento da liberdade humana. Nosso intuito, nesse texto, além da identificação e definição das bases normativas do pensamento dos clássicos, será o de reconstruir os traços das circunstâncias apontadas por eles como impeditivas à concretização do projeto do individualismo moral. Ao mesmo tempo, buscaremos ressaltar a perene relevância do enfoque sociológico do individualismo moral nas análises contemporâneas sobre o desenvolvimento humano, como o do economista Amartya Sen, centradas no enfoque dos pré-requisitos sociais indispensáveis ao desempenho individual.

Palavras-chave: Sociologia Clássica; Individualismo Moral; Desenvolvimento Humano.

\section{Individualistic morality and the classical sociological thought}

\begin{abstract}
The Classical sociology, even though has, among its main traits, a plurality of approaches, shares, nonetheless, a common normativity, a common perspective about what is a fair society. We argue, throughout the text, that departing from an individualistic normativity, Marx, Weber, Durkheim, Simmel and Tocqueville give us, by different ways, theories whose aim is to provide us practical knowledge on how to free individual capacity from social constraints. The universal individual is the goal. Not the group. Classical sociology, therefore, makes the diagnosis of the sources of exploitation and domination that prevent the free development of human freedom. Our aim, in this text, besides identifying the common normative ground that lies underneath the classical thoughts, is to reconstruct the social environments identified by them as blocking the project of individualistic self-development. At the end, we shall argue about the contemporality of the sociological approach on individualistic normativity in actual analysis on human development, as that of Amartya Sen, which focus on the social prerequisites of individual accomplishment.
\end{abstract}

Keywords: Classical Sociology; Individualistic morality; Human Development

\footnotetext{
${ }^{1}$ Doutorando no programa de pós graduação em Sociologia Política da Universidade Estadual do Norte Fluminense (UENF Darcy Ribeiro). E-mail: raphaeldeoliveirasoares@hotmail.com
} 


\section{Introdução}

A Sociologia Clássica, não obstante tenha, em seus fundamentos, claras pretensões científicas, fincadas em formulações e proposições formadas metodicamente, oriundas, em grande medida, dos modelos fornecidos pelas ciências naturais, tem, como pano de fundo de suas teorias, implícita ou explicitamente, uma normatividade bem estabelecida, ou seja, uma ideia clara e precisa do que seja um ordenamento social justo. A sociologia, como notou o sociólogo Frederich Vandenberghe (2012), é herdeira da filosofia moral. Argumentaremos que o individualismo moral, como orientação valorativa que prega que o objetivo da sociedade e de todas as suas instituições é permitir que os indivíduos, em sua universalidade, desenvolvam a totalidade de suas capacidades, perpassa a obra de todos os clássicos da sociologia. A teoria sociológica, de uma maneira geral, faz uma crítica imanente a modernidade, analisando os entraves que impossibilitam a realização de seus ideais, e não negando os ideais em si mesmos.

É preciso distinguir claramente, dessa forma, entre as distintas teorias da justiça, ou seja, as distintas concepções do que seja um ordenamento social "justo", tanto no plano coletivo quanto no da conduta individual. Como nos lembra Sandel (2013), as teorias da justiça da antiguidade partem da virtude, enquanto as modernas começam pela liberdade. Assim, princípio basilar da justiça antiga e medieval é tratar desigualmente os desiguais. Para determinar quem merece o que, com efeito, deve-se estabelecer quais virtudes são dignas de honra e recompensa e, por outro lado, quais são dignas de punições e desprestigio. As estratificações eram, portanto, consideradas como dadas, como naturais. No mundo antigo, a autonomia subjetiva é sempre limitada. $\mathrm{O}$ que é possível ao ser humano está fixado pela ordem cósmica que define o lugar a ele reservado. A sociedade é vista como um elemento integrante do mundo natural circundante. Na ordem feudal, por sua vez, a sociedade estruturava-se em torno de uma ética paternalista cristã, de modo que a sociedade se equiparava a uma família, com relações recíprocas de dependência e subordinação, que, no entanto, estabeleciam redes de obrigatoriedades entre seus diversos elementos (HUNT e SHERMAN, 2013). 
O individualismo moderno tem na universalidade, na generalidade de suas pretensões, a marca definidora, constitutiva, de seu caráter. A revolução Francesa, marco político-ideológico da modernidade, é notória por seu caráter ecumênico, por se dirigir ao homem em geral, independentemente de sua nacionalidade, pertencimento estamental, raça, gênero ou qualquer outra modalidade de estratificação. Todos são iguais perante Deus e perante a lei. O homem como tal estava no centro dos interesses daquele tempo. O grande formulador da moral moderna, nesse sentido, foi Immanuel Kant. Segundo Régis de C. Andrade (2002), sua filosofia moral é uma celebração da dignidade individual, tornando inviolável a esfera da consciência.

De acordo com a ética kantiana, a base de avaliação do ser humano transfere-se da ação para a consciência (SIMMEL, 2006). Se, dentro da tradição do catolicismo, os indivíduos eram avaliados segundo suas obras, a reforma protestante transfere a salvação ou condenação para o interior da consciência humana. Assim, estabelece-se a célebre dicotomia entre ética da convicção e ética da responsabilidade. Na ética protestante e o espírito do capitalismo, Weber (2005) argumenta que o Deus do Calvinismo não demandava de seus adeptos "boas obras", mas uma vida ética tomada como um "sistema", pautada em uma conduta cotidiana tida como virtuosa, independente de seus resultados práticos.

Segundo o pensamento kantiano, a dignidade do homem está em que, como ser racional, não obedece senão às leis que ele próprio estabeleceu. $O$ homem, diferentemente da ordem do mundo natural, não operaria segundo princípios de necessidade absoluta. A liberdade seria a propriedade pela qual a causalidade pode operar a partir de dentro, de um comando da vontade, independentemente de determinações por causas externas. O ser humano possui a capacidade de fazer algo ou não fazer, de deliberar, ponderar caminhos alternativos de conduta, que o mundo natural não tem como característica. A liberdade, portanto, aparece como autonomia, ou seja, a propriedade dos indivíduos legislarem a si próprios. "Que outra coisa pode ser a autonomia da vontade, então, senão autonomia, isto é, propriedade da vontade de ser lei para si própria?" (KANT, 2002, p. 99).

Segundo as palavras de Kant (2002), um imperativo a guiar a conduta moral é que os seres racionais são fins em si mesmos, isto é, são algo que não deve ser utilizado 
meramente como meio para um outro fim. Assim, diz ele: "Os seres racionais... chamamse pessoas, porque a natureza deles os distingue como fins em si mesmos, isto é, como algo que não deve ser utilizado meramente como meio, e por conseguinte impõe limites a todo arbítrio" (KANT, 2002, p. 97). O filósofo alemão, portanto, argumenta que a natureza humana se constitui como a suprema condição limitante a todos os outros fins postulados por outros indivíduos ou pela ordem social.

A ideia kantiana do individualismo moral, portanto, da noção de justiça que tem como fundamento a autonomia do indivíduo, sua igualdade como ser humano e a liberdade de sua vontade para decidir quais os caminhos lhe são adequados, é o alicerce a sustentar todas as diversas vertentes clássicas do pensamento sociológico. Mesmo em teorias macrossociológicas, pautadas em compreensões positivistas das ciências humanas, aderem a esse paradigma normativo. Anthony Giddens (1998, p. 147), dissertando sobre esse aspecto ambivalente da obra de Durkheim, argumenta que tem como intuito “...conectar sua discussão analítica (e sua rejeição) do individualismo como abordagem metodológica para a teoria social com sua concepção desenvolvimentista da emergência do individualismo como moralidade nascida do crescimento da divisão do trabalho diferenciada." A argumentação durkheimiana, em Da divisão do trabalho social (2010), parte da ideia de que a transição das sociedades tradicionais, segmentares, para as sociedades modernas, orgânicas, é um processo concomitante à individualização, de modo que a especialização do indivíduo de acordo com seus talentos e capacidades é o que deverá definir o lugar que cada um ocupará na sociedade, sobretudo na estrutura ocupacional.

Karl Marx, no mesmo sentido, em sua crítica a sociedade burguesa, a classifica como o último estágio da pré-história do Homem, isso é, a última sociedade estratificada antes que os indivíduos se tornassem livres para se autodeterminar e fazer, de fato, através de sua práxis, a História, e não serem meros objetos passivos dos imperativos da natureza e de estratos dominantes da sociedade. A existência das classes circunscreveria o limite real da liberdade do indivíduo, limitando o espaço de ação e as oportunidades abertas ao que cada um pode ou não alcançar. Segundo Marcuse (2004, p. 245), em Razão e Revolução, “O indivíduo é a meta. Esta tendência 'individualistica' é uma característica fundamental da filosofia marxista.” 
Alexis de Tocqueville (1987), na mesma chave normativa da liberdade individual, em Democracia na América, nos fornece uma das primeiras conceituações do individualismo como fenômeno sociológico. Em suas palavras, ao contrário do egoísmo, paixão irrefletida e exagerada por si mesmo, o individualismo seria a culminância de um longo trajeto histórico, fruto do avanço inevitável da igualdade. Diz Tocqueville (1987, p. 13): “... o gradual desenvolvimento da igualdade é uma realidade providencial. Dessa realidade, tem ele as principais características: é universal, é durável, foge dia a dia à interferência humana; todos os acontecimentos assim como todos os homens servem ao seu desenvolvimento". O progresso das ciências, das artes, da técnica, portanto, criou as condições ideais para a igualização das condições humanas, favorecendo desenvolvimentos tecnológicos e produtivos que levaram o status aristocrático a desaparecer em favor da disseminação de uma condição econômica, social e política comum, ou ao menos atingível por todos. A progressiva equalização das condições socioeconômicas e das capacidades humanas contribui, assim, de forma decisiva para o surgimento do sujeito universal.

No entanto, os produtos históricos da ação humana sempre se apresentaram, aos olhos dos clássicos da sociologia, em toda a sua complexidade. Max Weber, nesse sentido, verá no fenômeno da difusão e propagação da racionalidade formalinstrumental pelas distintas esferas da vida, em sua denúncia da progressiva perda de liberdade e de sentido da vida humana, como a patologia da modernidade. Em seus escritos políticos, sobretudo, o autor alemão aponta a perniciosa difusão da modalidade de ação e de dominação centradas na racionalidade referente a fins, suprimindo a importância não só das motivações com base em valores como bloqueando o surgimento de personalidades extraordinárias e inovadoras. A burocratização dos partidos políticos e do parlamento, em sua perspectiva, suprimiam a emergência de lideranças carismáticas que pudessem, de fato, renovar o parlamento e o próprio papel do Estado. Tal teria sido o legado dos anos do governo Bismarck à Alemanha de sua época. Weber (2015, p. 159), quando da renúncia de Bismarck ao cargo de chanceler, questionou: "Qual dos grandes partidos de seus seguidores exigiu ao menos uma explicação sobre as razões de sua demissão? Nenhum deles se mexeu; simplesmente se viraram para o novo sol.” Não havia lideranças políticas para tal. 
Em Simmel (2014), interlocutor de Weber, a tragédia da cultura se estabelece a partir do momento em que a ação humana, com seus objetos e práticas desenvolvidos para lidar com os desafios postos pela natureza e pela sociedade, engendra uma objetividade que se autonomiza e passa a funcionar por sua própria lógica, no que ele chama de separação entre cultura subjetiva e objetiva, resultando numa sempre crescente estranheza entre o sujeito e suas criações. De acordo com suas palavras: “[...] o sujeito vivencia incontáveis tragédias nesta profunda contradição de forma entre a vida subjetiva infatigável, mas temporalmente finita, e seus conteúdos, que, uma vez criados, são estáticos, mas tem uma validade atemporal" (SIMMEL, 2014, p. 77).

A partir dessa breve introdução, onde foram delineados os contornos do que se entende ser a moralidade subjacente aos escritos dos autores da sociologia clássica, i.e., o individualismo moral, buscaremos descrever, nas próximas seções, os contextos sociais e históricos que se constituíram, e se constituem, em travas, empecilhos, a plena realização do projeto normativo da modernidade. Se, por um lado, temos, nas tradições das sociedades antiga e feudal, uma miríade de relações familiares e religiosas, a submeter os indivíduos, por outro, na modernidade, temos os sistemas funcionalmente diferenciados, sobretudo o Estado moderno e o Capitalismo.

Por fim, chamaremos atenção para a atualidade dos clássicos para teorias contemporâneas do desenvolvimento humano, como o do economista Amartya Sen, que adere ao horizonte normativo do individualismo moral, ao mesmo tempo que identifica os pré-requisitos sociais indispensáveis ao desempenho individual, sobretudo no que se refere a infraestrutura de serviços públicos. $\mathrm{O}$ foco do economista indiano se concentra na noção de capacidades humanas (capabilities) de forma concomitante a pluralidade de instituições que são necessárias para que os indivíduos possam realizar suas capacidades individuais e estar aptos a fazer, de fato, escolhas. Diz ele, sobre a eficácia social dessa abordagem: "Ter mais liberdade melhora o potencial das pessoas para cuidar de si mesmas e para influenciar o mundo, questões centrais para o processo de desenvolvimento" (SEN, 2010, p. 33). 


\section{Antiguidade, Feudalismo e o Individuo}

Como dito, as teorias da justiça da antiguidade partem da virtude, enquanto as modernas começam pela liberdade. Platão, em A República (2014), nos descreve o que seria uma organização política justa, um regime político ideal. Sua proposta ideal de organização da polis era a de um governo aristocrático, em que a camada dirigente seria formada por Reis-filósofos. Aristoi, em grego, provém do vocábulo Arete, ou virtude, excelência. Portanto, um governo aristocrático seria o governo dos virtuosos. A virtude, nesse caso, seria o desenvolvimento da racionalidade humana e de sua sobreposição às paixões e aos instintos. As cidades, portanto, deveriam ser governadas por filósofos, que teriam passado pelo processo educacional necessário para engendrar a conduta guiada pela razão, para sair da caverna em direção à luz.

Para Platão, a política consistia em um saber especializado e exclusivo que deveria ser reservado a poucos. A democracia, por seu turno, em sua perspectiva, distribuía um tipo de igualdade, indiscriminadamente, tanto a iguais quanto aos desiguais, afrontando princípio basilar da justiça antiga, segundo o qual há que se tratar desigualmente os desiguais na medida de suas desigualdades. A democracia retratada por Platão, portanto, é um regime político completamente anárquico, no qual as classes e suas funções estão completamente embaralhadas, presa fácil ora da demagogia, ora da tirania (CHAUÍ, 2002).

Para o discípulo de Sócrates, é principalmente num Estado sob esse regime político que se encontram indivíduos de todos os tipos. Como um traje multicolorido, segundo suas palavras. A liberalidade promovida pela democracia promoveria um embaralhamento das posições "naturais" dos distintos grupos, minando a própria autoridade. Assim, “O Estado passa a insultar os que obedecem aos governantes, classificando-os como escravos voluntários e indivíduos imprestáveis, e louva e estima, tanto publica quanto privadamente, governantes que se comportam como governados e governados que se comportam como governantes" (PLATÃO, 2014, p. 354). Continuando em sua exposição: 
O clímax dessa liberdade para a multidão é atingido nesse Estado quando os escravos comprados [...] gozam de tanta liberdade quanto seus proprietários que pagaram por eles. E eu quase me esqueço de mencionar o grau de liberdade e os direitos de igualdade na relação entre homens e mulheres (PLATÃO, 2014, p. 355).

Na crítica Platônica, há a radicalização do elemento mais característico e atraente da democracia, ou seja, a liberdade, salientando-se a tolerância peculiar que viceja nesse regime político em relação aos hábitos e aos modos de vida de seus cidadãos. A democracia é vista como fonte de subversão, anarquia, de estratificações e hierarquias consideradas "naturais", tendo em vista a ideia antiga da existência de desigualdades naturais entre os indivíduos e entre os seres. O cultivo das virtudes que conferem excelência às distintas categorias de cidadãos, portanto, é considerado menos importantes do que o apoio recebido da maioria. Nas palavras de seu maior discípulo, Aristóteles (2009, p. 211):

[...] o direito ou a justiça, em um Estado popular, consiste em observar a igualdade em relação ao número, e não a que se regular por mérito. Segundo essa ideia do justo, é preciso forçosamente que a soberania resida na massa do povo, e que aquilo que ele tenha decretado seja definitivamente firmado como o direito ou o justo por excelência [...] (ARISTÓTELES, 2009, p. 211).

Para nós, modernos, a crítica nos parece estranha, tendo em vista que a autonomia do indivíduo, sua capacidade de agência para decidir sobre o caminho que lhe é mais adequado, é um dos pilares normativos de nossas sociedades. As liberdades de ação, de escolha e de pensamento, são fundamentais em nossas sociedades contemporâneas, centradas nos pressupostos morais do individualismo filosófico, em contraposição às cosmovisões antiga e medieval, cuja compreensão orgânica da sociedade estabelece a priori a posição que cabe a cada categoria de indivíduos. No mundo antigo, a autonomia subjetiva é sempre limitada. O que é possível ao ser humano está fixado pela ordem cósmica que define o lugar a ele reservado. A sociedade é vista como um elemento integrante do mundo natural circundante.

$\mathrm{Na}$ ordem feudal, a sociedade estruturava-se em torno de uma ética paternalista cristã, de modo que a sociedade se equiparava a uma família, com relações recíprocas de obrigatoriedade entre seus diversos elementos desiguais (HUNT e SHERMAN, 2013). 
Segundo Tocqueville (1987, p. 387), "A aristocracia fizera de todos os cidadãos uma longa cadeia que ia do campônio ao rei; a democracia rompe a cadeia e põe cada elo à parte.” A nobreza e o clero, nesse contexto, constituíam as duas vertentes da classe dominante, que, no entanto, possuíam um amplo leque de obrigações para com a manutenção dos servos sob os seus domínios. Karl Polanyi, em seu clássico A grande transformação (2000), nos mostra todas as regulações tradicionais, que normatizavam a utilização do trabalho e da terra, e que tiveram que ser rompidas pelo Estado absolutista para que a força de trabalho humana pudesse ser transformada em mercadoria, isso é, para que o indivíduo se desprendesse de todas as relações de dependência que o prendiam a terra e às relações de vassalagem.

O processo de cercamento dos campos, nesse sentido, aparece na história inglesa como o início da ruptura com o modo de produção feudal. A revolução agrícola precedeu a revolução industrial. Ao transformar as terras que eram de uso comum em pastagens, os lordes e nobres, aburguesando-se, abalaram profundamente os alicerces daquela ordem social, assentada no campesinato e na ligação umbilical que havia até então entre o homem e o campo. O mesmo se passava nas cidades, sob o domínio das guildas, que dominavam o acesso às profissões artesanais e aos mercados urbanos. As corporações dos ofícios urbanos absorviam por completo os indivíduos, não apenas como associações de indivíduos buscando vantagens econômicas, mas sim como fato social total. De acordo com Simmel (2014, p. 24):

\footnotetext{
A corporação medieval integrava o homem por inteiro; uma corporação de tecelões não era uma mera associação de indivíduos que se limitava a cuidar dos simples interesses de seus membros, mas sim uma comunidade de vida, seja em aspectos técnicos, sociais, religiosos, políticos, seja em outros aspectos a mais (SIMMEL, 2014, p. 24).
}

Para Robert Nisbet (2009) as antigas relações entre grupos de homens e parcelas de terra, entre comunidades organizadas e unidades territoriais, constituíam o fundamental da história política desde tempos imemoriais. A modernidade, assentada no Estado moderno e no capitalismo, não só provocou devastadores efeitos de desenraizamento, culminando na expulsão em massa dos camponeses de terras habitadas desde antanho, como já exposto, como erodiu as bases da estrutura patriarcal 
e das relações de parentesco vigentes, e a hierarquia interna que lhes é constitutiva. Ao modificar a estrutura da propriedade, limitando a liberdade testamentária do patriarca, o forçando a uma divisão igualitária das posses, os legisladores revolucionários solapavam as bases da solidariedade econômica das famílias, debilitando-a. O indivíduo, portanto, e não o grupo, era o herdeiro do desenvolvimento histórico.

A ordem econômica de mercado teve que contar com a ação deliberada do Estado mercantilista para romper com todas as barreiras protecionistas que restringiam as condições em que se davam os intercâmbios econômicos dentro das cidades e no campo. A terra e o trabalho estavam envoltos em uma estrutura social tradicional que estipulava inúmeros ritos e tabus. Não só isso. Havia todo um conjunto de legislações que positivavam essas relações, e que tiveram que ser rompidas pelo próprio processo legislativo, dentro dos poderes constituídos. Segundo Nisbet (2009, p. 74), foi “[...] a união das forças legislativas e econômicas que trabalhavam para destruição de grupos e associações nascidas na idade média [...]”.2 (Tradução nossa).

Com efeito, diversas leis de assistência aos pobres, as poor laws, haviam sido estabelecidas durante séculos, no sentido de garantir subsistência aos habitantes de determinada localidade, garantindo-lhes o direito à vida. Tais legislações foram frontalmente atacadas pelos economistas liberais. A criação de um mercado de trabalho nacional partia da premissa de que os trabalhadores ofereceriam sua mão de obra em troca de salário. A perspectiva da fome no horizonte de expectativa, nesse caso, era crucial como motivação subjetiva. Nas palavras de Polanyi (200o), a tradicional unidade da sociedade cristã foi cedendo espaço a uma negação de responsabilidade da parte das classes dominantes em relação aos seus compatriotas, de modo que "[...] se os trabalhadores estavam fisicamente desumanizados, as classes dominantes estavam moralmente degradadas. A unidade tradicional de uma sociedade crista cedia lugar a uma negação da responsabilidade por parte dos ricos em relação às condições dos seus semelhantes" (POLANYI, 200o, p. 126).

Durkheim, por sua vez, em seu estudo Da divisão do trabalho social (2010), nos mostra como a especialização e a individualização é uma decorrência, em parte, de novas

\footnotetext{
${ }^{2}$ Segundo Nisbet (2009, p. 74), foi “...la unión de las fuerzas legislativas y económicas que trabajaban por la destruición de grupos y asociaciones nacidos en la edad media”.
} 
condições demográficas da existência social. Segundo ensinamento Darwinista, espécies que compartilham o mesmo espaço só podem garantir sua sobrevivência na medida em que lutam por recursos diferentes. No caso das sociedades humanas, a especialização do trabalho é a via. Com o esvanecimento da sociedade segmentária, tradicional, os indivíduos são expostos a interrelações distintas das que havia antes. Não só se verifica o aumento do contingente populacional, como, principalmente, a densidade das relações interpessoais. Esses mesmos indivíduos, imbricados em teias de relações cada vez mais numerosas e complexas, são impelidos a especialização, a fim de sobreviver. Diz Emile Durkheim (2010, p. 252):

[...] a divisão do trabalho progride tanto mais quanto mais houver indivíduos suficientemente em contato para poderem agir e reagir uns em relação aos outros. Se conviermos em chamar de densidade dinâmica ou moral essa aproximação e o intercambio ativo que dele resulta, poderemos dizer que os progressos da divisão do trabalho são diretamente proporcionais à densidade moral ou dinâmica da sociedade (DURKHEIM, 2010, p. 252).

Simmel, em seu texto As grandes cidades e a vida do espírito (2005), desenvolve a mesma linha de raciocínio: "A vida na cidade pequena, tanto na Antiguidade como na Idade Média, impunha ao singular limites de movimento e de relações em direção ao exterior e de autonomia e diferenciação em direção ao interior, sob os quais o homem moderno não conseguiria respirar" (Simmel, 2005, p. 584). Para Jesse Souza (2014, p. 11), comentando a obra de Simmel, “[...] o contrário da liberdade não seria a mera existência de vínculos enquanto tais, mas a dependência em relação a poucos, ou, no caso limite, a um só." Para Simmel, portanto, na mesma direção do argumento de Durkheim, a multiplicidade de vínculos e relações é a própria precondição objetiva para o aparecimento da noção de indivíduo, da própria ideia de que o indivíduo poderia possuir uma identidade própria apartada do social.

A partir da reconstituição dos argumentos de alguns textos clássicos das ciências sociais, perceberemos que o indivíduo é fruto de um longo processo histórico. $\mathrm{O}$ indivíduo não é apenas, como uma perspectiva liberal poderia sugerir, uma entidade natural a priori que deve ser protegida do poder incontrastável do Estado, mas o próprio indivíduo é, em grande parte, uma criação do Estado. O Estado, em seu processo de 
centralização e aglutinação do poder de coerção física e, sobretudo, simbólica, esvaziou os corpos intermediários, outrora locus de pertencimento e identificação, mediante a criação de uma ficção jurídica chamada indivíduo. Nesse sentido, a jurisdição de um corpo administrativo em expansão destruiu todas as identidades pré-políticas que os indivíduos possuíam, impondo, dentre outras coisas, sua monopolização do direito de classificar. As classificações estatais, assim, passam a ser as únicas legítimas e reconhecidas, positivando, assim, o desprezo rousseaniano pelas “associações parciais”.

\section{Alienação, Fetichismo e o Indivíduo}

O declínio da belle époque, período que antecede a Primeira Guerra Mundial, é marcado pelos primeiros desapontamentos e decepções engendrados pelas promessas não cumpridas do projeto emancipatório do iluminismo. O desenvolvimento da cultura, entendido como o avanço do domínio do homem sobre a natureza, a expansão das atividades produtivas, o progresso da ciência e da tecnologia, a instituição de liberdades civis básicas, a instauração de regimes democráticos representativos, enfim, o surgimento e a consolidação dos marcos institucionais característicos da modernidade, não levaram os indivíduos à conquista da liberdade e a superação do estado de submissão aos flagelos que marcam a humanidade desde os primórdios. Pelo contrário, o desenvolvimento de todos os progressos humanos em suas mais diversas áreas de atividade foi tornando os indivíduos cada vez mais submetidos ao funcionamento do fruto de suas atividades. As obras humanas, projetadas para serem instrumentos de promoção de seu bem-estar, instauraram um nível de escravidão física e mental intolerável para muitas pessoas, fazendo-as perecer em escala industrial.

A primeira grande formulação dessa problemática moderna fundamental, a questão da severa submissão do homem aos objetos e práticas oriundas de suas atividades, está nas obras de Rousseau. No Discurso sobre a origem e o fundamento das desigualdades entre os homens (2005), o bucolismo do filósofo genebrino nos mostra o trajeto fúnebre seguido pelo homem, de um hipotético estado de natureza, onde há pouca sociabilidade e prevalência de um modo de vida simples, quase instintivo, em direção a sua escravização pelos requintes e promessas de gozo e segurança 
disponibilizados pela sociedade. As promessas da civilização encheram os indivíduos de vaidades, cujas perspectivas de realização, nunca alcançadas, sempre foram a estratégia mais bem formulada pelos beneficiários de uma ordem social iniqua, onde parcelas diminutas da sociedade se beneficiam. Assim, Rousseau (2005, p. 169) nos diz:

[...] eis a prova de que a maioria de nossos males é obra nossa e de que os teríamos evitado quase todos conservando a maneira de viver simples, uniforme e solitária que nos era prescrita pela natureza. Se ela nos destinou a sermos sãos, quase ouso assegurar que o estado de reflexão é um estado contrário à natureza e que o homem que medita é um animal depravado (ROUSSEAU, 2005, p. 169).

Para Carlos Nelson Coutinho (2011, p. 21), “[...] as reflexões filosóficas de Rousseau antecipam em muitos pontos a ontologia do ser social de Hegel e, sobretudo, de Marx”. O progresso da civilização, antes de aumentar a felicidade do maior número de pessoas, maximizando seus prazeres e reduzindo suas dores, levou a níveis de exploração econômica e de dominação política e psicológica em escalas sem precedentes nas sociedades ditas "tradicionais", ainda que sob esse rótulo coexistam as mais díspares experiências históricas. Os homens submetem-se aos seus próprios feitos, se tornando escravos dos produtos de sua atividade. Em resposta paradoxal ao problema da alienação, a proposta rousseaniana em O Contrato Social (2011) advoga uma alienação total voluntária do indivíduo a coletividade. Diz ele: "Essas cláusulas, quando corretamente entendidas, se reduzem todas a uma só, a saber: a alienação total de cada associado, com todos os seus direitos, a toda a comunidade" (ROUSSEAU, 2011, p. 66). Portanto, propõe um novo contrato social, feito, agora, sobre novas bases, racionais, e não mais o contrato histórico, erigido sobre a contingência, a desigualdade material e a força.

No O capital (2002), a crítica de Marx à alienação do homem, seu estranhamento em relação a si mesmo e aos produtos de sua atividade, se dá pela análise da mercadoria. A mercadoria como expressão de uma relação social historicamente especifica é a expressão da sociedade dividida em classes, onde uns produzem e outros se apropriam do que é produzido. Onde a uns é permitido a autorrealização de suas múltiplas potencialidades, de suas capacidades humanas, enquanto para outros resta a redução a um estado abaixo da humanidade, a coisa. A aparição do "trabalho livre" consistiu na 
expropriação de todos os meios de vida tradicionais de populações inteiras, obrigandoas a venderem o que lhes restava, sua força de trabalho. A coisificação da força de trabalho, a redução das capacidades laborais do trabalhador, sua perícia específica, ao valor de troca, medida de valor homogênea, destrói a individualidade e as características pessoais do indivíduo e de sua produção. Se formos mais atrás na história da filosofia, veremos, em Locke, a ideia do trabalho como parte fundamental da essência do ser humano, sendo o próprio fundamento de legitimação da propriedade. Nesse sentido, a alienação em relação à atividade produtiva e seus produtos era entendida como um desencontro do ser humano consigo mesmo.

A abolição da destreza é o resultado da mecanização e racionalização do trabalho. O trabalhador se torna apêndice da máquina. $\mathrm{O}$ progressivo distanciamento do trabalho mental e do trabalho manual degrada as capacidades intelectuais do trabalhador de conceber o fruto do seu trabalho de uma forma total. Tal concepção, com efeito, torna-se mais contundente se atentarmos para as premissas filosóficas da filosofia marxista, o individualismo moral, o qual temos exposto ao longo do texto. Se o intuito da revolução marxista passa pela liberação do homem dos constrangimentos produzidos pelo modo de produção vigente, sua divisão do trabalho e, principalmente, suas formas de divisão da propriedade do produto do trabalho, é necessário atentar para o papel fundamental exercido, nessa concepção, pelo trabalho como forma de autorrealização individual.

Max Weber, muito menos otimista em relação às possibilidades de revolução, argumentava que um regime socialista não só não livraria o homem comum das formas cotidianas de exploração e dominação as quais se submetia, como, pelo contrário, o colocaria sob o jugo de instâncias burocráticas muito mais eficientes em seu controle sobre a vida humana do que a administração pública limitada pelo modo capitalista de produção. No capitalismo, não obstante os indivíduos estejam constantemente constrangidos pelos imperativos do Estado e do mercado, há a existência de um nível de pluralismo que, de algum modo, protege o indivíduo de sucumbir por completo a uma instância que se lhe apresenta como totalitária. A burocratização da vida, como meio de institucionalização de uma racionalidade estratégica, é um fato inexorável em um mundo secularizado, seja ele socialista ou capitalista. A temática weberiana, com efeito, 
diagnostica os males trazidos para a vida humana da generalização da racionalização referente a fins sobre todas as esferas da vida. O agir motivado por interesses, por objetivos, dominando a existência e empobrecendo a vida.

De acordo com Vandenberghe (2012, p. 50), "[...] pode-se dizer que a racionalização formal de Weber é rigorosamente um sinônimo de reificação de Marx.” A obra do filósofo Georg Lukács (1974), por sua vez, se direciona no sentido de realizar uma síntese da obra dos dois cânones sociológicos alemães. Seu conceito de reificação é a fusão da teoria da alienação e do fetichismo da mercadoria, de Marx, e o fenômeno da difusão e propagação da racionalidade formal-instrumental pelas distintas esferas de valor cultural, de Weber. O desenvolvimento teórico realizado por Lukács vai na direção da identificação da difusão da impessoalidade, do cálculo, da estipulação de regras formais que a todos submetem, próprias da racionalização do modo de produção capitalista, a todas as esferas da vida. "A economia, o direito e o Estado aparecem como sistemas fechados que dominam toda a sociedade em virtude da perfeição de seu próprio poder, pelas suas leis próprias e imanentes" (LUKÁCS, 1974, p. 240). A reificação é a submissão dos seres humanos às leis prevalecentes nos diversos sistemas funcionalmente diferenciados da sociedade moderna. A modernidade, portanto, traz consigo o perigo da extinção da autonomia humana, o cerceamento total da possibilidade do indivíduo estipular as próprias regras sob as quais deseja se submeter, ruindo as possibilidades de realização do imperativo moral kantiano.

A filosofia de Lukács, enveredando pela seara crítica aberta por Marx e Weber, nos mostra como a humanidade se tornou vítima de seu próprio sucesso. A fim de realizar seus intentos de dominação sobre a natureza e sobre os outros homens, a necessidade da racionalização, do cálculo, da continuidade temporal das tendências próprias aos sistemas sociais, de suas "leis”, acabou por levar a tragédia da destruição do presente. Talvez aí resida o grande problema. A vida cotidiana, o hoje, que é onde, de fato, a vida é vivida, como os sábios ensinamentos do Budismo jamais vão nos deixar esquecer, acaba sendo reduzido a um ponto homogêneo dentro de uma linearidade, dentro de um projeto de mundo que parece sempre buscar nas tendências das trajetórias passadas as possibilidades de realização do futuro, se esquecendo talvez do único espaço temporal no qual a ação é possível, i.e., no hoje, no aqui e no agora. 
Na mesma chave normativa, Tocqueville (1987) argumenta que a modernidade, não obstante alicerçada em valores liberais, guiada para a liberação das potencialidades individuais, engendrou uma nova forma de poder, mais irresistível e onipresente do que qualquer outro tipo pretérito. A democracia, e a ideia de igualdade que lhe é constitutiva, ainda que faça parte de um movimento histórico mais amplo de igualização das condições humanas, favorecido por desenvolvimentos ideológicos, tecnológicos e produtivos, onde o status aristocrático desaparece em favor da disseminação de uma condição econômica, social e política comum, ou ao menos atingível por todos, é, não obstante, um sistema de poder político, cuja sofisticação e abrangência, desde cedo, chamou atenção dos observadores mais argutos.

O movimento de igualização das condições, impulsionado pelo progresso das ciências, das artes, da técnica, etc., nesse sentido, criou as condições ideais para o desenvolvimento dos novos mecanismos de dominação. Se os estratos intermediários do mundo feudal foram sendo dissolvidos, tanto pela ação política revolucionária quanto pela erosão das bases ideológicas de sua legitimidade, o que surge em seu lugar, como continuidade histórica da centralização iniciada pelos monarcas absolutos, é um aparato estatal burocrático que, profissionalizando-se e racionalizando-se, erige um sistema de controle que, através de meios muito mais eficazes e sutis, é capaz de enredar os indivíduos sem que esses, nem ao menos, notem. Diz o pensador francês:

[...] no século XVIII a administração pública já era muito centralizada, muito poderosa, prodigiosamente ativa. Estava incessantemente auxiliando, impedindo, permitindo. Tinha muito a prometer, muito a dar. Já influía de mil maneiras, não apenas na condução geral dos assuntos públicos, mas também na sorte das famílias e na vida privada de cada homem (TOCQUEVILLE, 2009, p. XLIII).

Para Tocqueville, como grande pensador liberal que foi, a ameaça à liberdade que a igualdade poderia constituir sempre esteve no centro de suas indagações. Como dito, a destruição dos mecanismos tradicionais de moderação do poder central, como eram os estamentos feudais e as corporações de ofício, por exemplo, propiciaram uma hipertrofia e centralização do poder, mediados por mecanismos burocráticos de organização, jamais antes atingido pelos estados pré-modernos. O poder social se 
tornou, assim, irresistível. Não só em termos de capacidade burocrática de controle e coerção, mas, sobretudo, moralmente. A opinião da maioria se tornou a fonte de legitimação do poder social, a base de justificação do poder público, constituindo-se em forte empecilho a aparição de opiniões divergentes. A tendência à homogeneização, que tanto serviço presta a atividade de dominar, tendo em vista a não perda de tempo com idiossincrasias, sufoca a liberdade individual.

Em Simmel (2005), por sua vez, há a demonstração de como a vida psicológica dos indivíduos nas grandes cidades sofre severos impactos. Uma das características do ser humano moderno, urbano, nesse sentido, seria o aumento do intelectualismo, em detrimento das relações pautadas pelo sentimento e pelo afeto, próprias do mundo tradicional. O entendimento lógico, como salienta Simmel, despreza o individual, tendo em vista sua impossibilidade de generalização. Símbolos máximos da modernidade, a difusão geral do relógio de bolso e da economia monetária seriam frutos da necessidade de sincronização da atividade de diversos indivíduos, na crescente divisão do trabalho provocada pelas novas condições demográficas da vida. O sucesso da divisão do trabalho, ao exigir do singular realizações cada vez mais unilaterais, atrofia a personalidade individual como um todo, como um "grão de areia em uma organização monstruosa de coisas e potências" (SIMMEL, 2005, p. 588).

Como exposto ao longo do texto, a modernidade é interpretada, pelos seus autores clássicos, em toda a sua ambivalência. Ao mesmo tempo em que a liberdade individual, como horizonte normativo, foi possibilitada pela remoção de uma miríade de relações e instituições que pregavam a subordinação do indivíduo a totalidade social, essa mesma ação, liberta dos constrangimentos tradicionais, engendrou novas formas, agora impessoais, de dominação e exploração. Contudo, se há autores com diagnósticos mais lúgubres sobre as possibilidades futuras da libertação humana, como Max Weber, há, por outro, autores como Marx, ${ }^{3}$ que entreveem, em uma sociedade futura, novas

\footnotetext{
3 "Só no século XVIII, na 'sociedade burguesa', as diferentes formas do conjunto social passaram a apresentar-se ao indivíduo como um simples meio de realizar seus objetivos particulares, como uma necessidade exterior. Mas a época que dá origem a este ponto de vista, o do indivíduo isolado, é precisamente aquela em que as relações sociais atingiram o seu máximo de desenvolvimento. O homem é, no sentido mais literal, um dzoon politikhon, não só um animal sociável, mas uma animal que só em sociedade pode isolar-se" (MARX, 2011, p. 226).
} 
formas de organização social que possam libertar os indivíduos das fontes de exploração e dominação que os impedem de auto realizar-se.

A ambivalência da sociedade descrita nos clássicos é resgatada, contemporaneamente, por linhas teóricas que enfatizam o indispensável suporte fornecido pela sociedade à realização das liberdades individuais. Marx e Engels, na Ideologia Alemã (2007, p. 92), nos ensinam que “[...] é somente na comunidade que cada indivíduo possui os meios de desenvolver suas faculdades em todos os sentidos; é somente na comunidade que a liberdade pessoal é possível.” Amartya Sen (2010), Nobel de economia, é um dos proponentes contemporâneos dessa acepção de justiça que reconhece, na liberdade individual, o fundamento do bem-estar social e do desenvolvimento das nações. De acordo com suas palavras: "[...] temos de considerar a liberdade individual um comprometimento social" (SEN, 2010, p. 10).

O foco que o economista indiano concentra nas capacidades (capabilities) abrange, principalmente, a pluralidade de instituições que são necessárias para a realização das capacidades individuais. Nem a supressão de liberdades políticas e civis, em proveito do desenvolvimento econômico, nos parece mais adequado, nem, tampouco, a garantia de liberdades abstratas, sem levar em devida conta a infraestrutura de serviços públicos com a qual os indivíduos contam para promover seu próprio desenvolvimento. Assim:

\footnotetext{
Uma variedade de instituições sociais - ligadas à operação de mercados, a administrações, legislaturas, partidos políticos, ongs, poder judiciário, mídia e comunidade em geral - contribui para o processo de desenvolvimento precisamente por meio de seus efeitos sobre o aumento e a sustentação das liberdades individuais (SEN, 2010, p. 377).
}

A complexa relação entre indivíduo e sociedade se resume em seu dubio caráter, constituindo-se, simultaneamente, em fonte de repressões e de oportunidades, em problema e solução. Por fim, poderíamos considerar que, do ponto de vista da ação coletiva, da organização política das sociedades modernas, tem-se que o foco na moralidade individual ainda é um ponto de vista promissor para as mazelas que nos acometem. Diante da emergência contemporânea de líderes políticos populistas, em uma conjuntura em que há um inegável mal estar em relação às precárias respostas 
dadas pelos sistemas políticos nacionais para as incertezas que dominam atualidade, o olhar sobre o indivíduo enquanto tal, suas capacidades e suas responsabilidades, pode ser um antidoto contra a procura por "salvadores da pátria”, proponentes de soluções radicais e supostamente miraculosas. A moralidade do indivíduo é o resgate da força do homem simples, de sua capacidade de decidir e de agir sobre o mundo com o qual se defronta, abrindo possibilidades para formas menos violentas e excludentes de vida social. É a negação das “respostas vindas de cima”. Como nos recorda Amartya Sen (2010, p. 361), “[...] o argumento do apoio social para expandir a liberdade das pessoas pode ser considerado um argumento em favor da responsabilidade individual, e não contra ela.”

\section{Conclusão}

Argumentamos, ao longo do texto, que a sociologia clássica partilha, entre seus principais autores, de uma normatividade comum, isso é, de um mesmo ideal de sociedade justa. O individualismo moral, centrado na ideia do ser humano universal, livre, igual e em busca da felicidade, presente tanto em Marx, quanto Weber, Durkheim, Simmel e Tocqueville, fornece o substrato normativo que fundamenta os diagnósticos dos problemas aos quais eles endereçavam soluções. A sociologia clássica faz o diagnóstico das fontes de exploração e dominação que impedem o livre desenvolvimento da liberdade humana, não só no reconhecimento da necessidade de superação do aprisionamento individual em ordenamentos sociais de inspiração na antiguidade e no

feudalismo, fundadas em hierarquias cosmológicas e familiares, como apontando a necessidade de superação da alienação promovida pela autonomização dos sistemas funcionalmente diferenciados do mundo moderno, sobretudo a economia capitalista e o Estado.

A relevância de tal incursão teórica se encontra, em nossa perspectiva, na sempre recorrente ameaça, impulsionada pelos mais diversos interesses, de negação da realização do projeto moderno de universalização da liberdade individual. Nos tempos atuais, da alvorada do século XXI, o atordoamento prevalece frente a crescente complexidade social, redundando na onda beligerante e facciosa que se instalou no mundo, mesclando racismo, nacionalismo e xenofobia, em conjunto com elevados níveis 
de desigualdade, apartando segmentos expressivos da população mundial das benesses e das oportunidades produzidas pela civilização moderna. A remoção de direitos e o retrocesso dos avanços democráticos são apanágios, características, da atual conjuntura, minando as perspectivas de universalização da condição humana. O individualismo moral, centrado na universalidade da dignidade da pessoa humana, é um valor a ser constantemente defendido.

O que se percebe, portanto, como desafio a harmonia das sociedades modernas, é justamente a efetividade de suas pretensões a universalidade do ser humano, contra todas as pressões centrífugas nos impelem à desigualdade e à diferença. $\mathrm{O}$ ecumenismo da declaração dos direitos do homem e do cidadão, culminância do processo revolucionário francês, marco político-ideológico da modernidade, se dirigia para o "homem" em abstrato. Restrições de gênero, raça, renda, idade, religião, ideologia política, sempre foram princípios de delimitação tanto do contingente populacional apto a participar dos eventos políticos de uma dada comunidade quanto dos beneficiários das ações do poder público. As propostas de restrição do demos são persistentes e sempre renovadas, buscando tanto barrar os caminhos que levam às posições estatais como distorcer a fonte normativa do regime, a justificação de sua existência e de suas ações.

Ao esclarecer-se os fundamentos normativos da teoria sociológica clássica, portanto, busca-se chamar atenção para a incompletude de seu projeto, que, longe de representar um progresso linear a um estado social idílico, numa utopia rousseauniana onde todos os indivíduos, associados, tomariam os rumos da sociedade em suas mãos, a universalização dos direitos humanos é sempre um objetivo fugidio, precariamente alcançável, presa fácil do embate movido diuturnamente pelos os homens, desde tempos imemoriais, em sua implacável vontade de poder.

Concomitantemente, a perene relevância dos ensinamentos dos clássicos sociológicos jaz em que não apenas nos mostram as fontes de exploração e dominação a impedir a realização do individualismo, como ressaltam a importância incontornável das precondições sociais para o mérito, para o bom desempenho individual. Amartya Sen (2010), Nobel de economia, é um dos proponentes contemporâneos de uma acepção de justiça que tem como fundamento reconhecer que a consolidação de um bem-estar social e de uma sociedade minimamente justa não se resumem a garantia de direitos 
civis, normatizações defensivas contra a arbitrariedade de qualquer poder público ou privado. A garantia de direitos formais a indivíduos e coletividades que sofrem de má nutrição, baixa expectativa de vida, escasso acesso à rede de ensino e outras mazelas, de nada valem. Sem o devido suporte social, o indivíduo não encontra as possibilidades de realizar suas capacidades.

Ao mesmo tempo, a moralidade individual pode ser encarada como trincheira de esperança frente a onda populista e facciosa que assola os tempos contemporâneos. Indivíduo universal, que todos nós somos, independente de categorias coletivas que nos aprisionam e nos delimitam. Na responsabilidade do indivíduo comum, consigo mesmo, com o próximo e com a natureza, pode estar a força sobre a qual se assentará uma ordem social mais harmônica e menos desigual, trazendo dias em que os avanços da civilização possam ser usufruídos de maneira coletiva, nos afastando das "ilhas de prosperidade", cercadas de violência e miséria, que caracterizam o mundo contemporâneo.

\section{Referências}

ANDRADE, Regis de Castro. Kant: A liberdade, o indivíduo, a república. In: WEFFORT, Francisco C. (Ed.). Os Clássicos da política: Burke, Kant, Hegel, Tocqueville, Stuart Mill, Marx. 10.ed. São Paulo: Ática, 2002.

ARISTÓTELES. A Política. Bauru, SP, Edipro, 2009.

CHAUI, Marilena. Introdução à história da filosofia: dos pré-socráticos a Aristóteles, volume 1. São Paulo, companhia das letras, 2002.

COUTINHO, Carlos Nelson. De Rousseau a Gramsci: ensaios de teoria política. São Paulo, Boitempo, 2011.

DURKHEIM, Émile. Da divisão do trabalho social. 4.ed. São Paulo: Martins Fontes, 2010.

GIDDENS, Anthony. Política, sociologia e teoria social: encontros com o pensamento social clássico e contemporâneo. São Paulo: UNESP, 1998.

HUNT, E.K. e SHERMAN, Howard. História do pensamento econômico. Petrópolis, RJ,Vozes, 2013. 
KANT, Immanuel. Textos de Kant. In: WEFFORT, Francisco C. (Ed.). Os Clássicos da política: Burke, Kant, Hegel, Tocqueville, Stuart Mill, Marx. 10.ed. São Paulo: Ática, 2002.

LUKÁCS, Georg. História e consciência de classe: estudos de dialética marxista. Porto, 1974 .

MARCUSE, Herbert. Razão e revolução: Hegel e o advento da teoria social. Tradução de Marília Barroso. 5.ed. São Paulo: Paz e Terra, 2004.

MARX, Karl. O Capital: crítica da economia política: Livro 1. 20.ed. Rio de Janeiro: Civilização Brasileira, 2002.

A questão judaica. São Paulo: Centauro, 2005.MARX, Karl. Contribuição à crítica da economia política. São Paulo, Martins Fontes, 2011.

; ENGELS, Friedrich. A ideologia alemã. São Paulo, Martins Fontes, 2007.

NISBET, Robert. La formación del pensamiento sociológico, vol.1. Amorrortu Editores España SL; Edição: 2, 2009.

PLATÃO. A República (ou da justiça). São Paulo, Edipro, 2014.

POLANYI, Karl. A Grande transformação: as origens da nossa época. 2.ed. Rio de Janeiro: Elsevier, 2000.

ROUSSEAU, Jean-Jacques. Discurso sobre a origem e os fundamentos da desigualdade entre os homens. $3^{\underline{a}}$ ed. São Paulo, Martins Fontes, 2005.

Do contrato social ou princípios do direito político. SP, Penguim classics, companhia das letras, 2011.

SANDEL, Michael. Justiça - O que é fazer a coisa certa. Rio de Janeiro, 10 ${ }^{a}$ edição, civilização brasileira, 2013.

SEN, Amartya. Desenvolvimento como liberdade. São Paulo, Companhia das letras, 2010.

SIMMEL, Georg. Questões fundamentais da sociologia: indivíduo e sociedade. Rio de Janeiro, Jorge Zahar, 2006.

. O dinheiro na cultura moderna. In: SOUZA, Jesse e OELZE, Berthold. Simmel e a modernidade. Brasília, editora universidade de Brasília, 2ª̣ed., 2014.

O conceito e a tragédia da cultura. In: SOUZA, Jesse e OELZE, Berthold. Simmel e a modernidade. Brasília, editora universidade de Brasília, 2ª̣ed., 2014. 
As grandes cidades e a vida do espírito. MANA 11(2):577-591, 2005.

SOUZA, Jessé e OELZE, Berthold. Simmel e a modernidade. Brasília, editora universidade de Brasilia, $2^{2}$ ed., 2014.

TOCQUEVILLE, Alexis de. A democracia na América. 2.ed.: Itatiaia, 1987.

O antigo regime e a revolução. SP, Martins Fontes, 2009.

VANDENBERGHE, Frédéric. Uma história filosófica da sociologia alemã: alienação e reificação. Vol, 1. Marx, Simmel, Weber e Lukács. São Paulo, Annablume, 2012.

WEBER, Max. A Ética protestante e o "espírito" do capitalismo. São Paulo: Companhia das Letras, 2005.

Escritos políticos. São Paulo, Folha de S. Paulo, 2015. 